\title{
Compression Deformation Mechanisms of Nanocrystalline Ni Prepared by Plasma Evaporation Method
}

\author{
Zhu Rongtao, Li Yanfeng \\ China University of Mining and Technology, Xuzhou 221116, China
}

\begin{abstract}
To investigate mechanical behaviors and deformation mechanisms of nanocrystalline materials, bulk nanocrystalline $\mathrm{Ni}$ samples were prepared by a plasma evaporation method combined with hot pressure sintering. The compressive mechanical properties of the bulk samples were tested under different quasi-static strain rates at room temperatures, and the evolution of the microstructure of the bulk sample before and after compression was studied. Results indicate that the bulk samples show a good combination of strength and ductility during the compressive testing. Meanwhile, the grain size of the compressed sample decreases compared with that of the sintered sample, while the microstrain of the grain increases after compression. Based on experimental results, it is can be inferred that both grain boundary dislocation glide and grain boundary sliding are the main deformation mechanisms for the bulk NC Ni samples.
\end{abstract}

Key words: bulk nanocrystalline $\mathrm{Ni}$; mechanical behavior; deformation mechanism; microstructure

Nanocrystalline (NC) materials are currently of great interests due to their unusual mechanical properties, such as ultra-high yield and fracture strength and enhanced superplastic formability. The special mechanical behaviors indicate that NC materials have different fundamental physical deformation mechanisms compared with their conventional coarse-grained counterparts. Many experiments ${ }^{[1-3]}$ and theoretical predictions ${ }^{[4-8]}$ have been carried out to investigate the mechanical behavior of $\mathrm{NC}$ materials. Most of them considered that the deformation mechanism of NC materials is dependent on grain size and strain rate, and the grain boundary mediated mechanism cannot be neglected during the plastic deformation. However, the deformation mechanism of $\mathrm{NC}$ materials is still not well-understood so far. Even for the same material, the deformation mechanism will also vary with further deformation.

Recently, some new methods through investigating the evolution of microstructure during plastic deformation ${ }^{[9-13]}$ have been developed to study the deformation mechanism of NC materials. Although stress modes and impurity elements may affect the microstructure evolution of NC materials, most of them found that the stability of microstructure is associated with grain boundaries. The similar results ${ }^{[14-16]}$ were obtained in molecular dynamic simulation.

In the present paper, to investigate mechanical behaviors and deformation mechanisms of NC materials, bulk NC Ni samples were prepared by a plasma evaporation method combined with hot pressure sintering. Then mechanical properties including strength, elongation to failure and strain rate sensitivity of the samples were studied under unaxial compressive loading at different strain rates and the stability of the microstructure of bulk sample was analyzed during the plastic flow. Finally, the underlying deformation mechanisms were predicted based on these results.

\section{Experiment}

The bulk NC Ni samples were prepared by a plasma evaporation method combined with hot pressure sintering. First, NC powder was prepared by a plasma evaporation system. As shown in Fig.1, the plasma evaporation system contained

$\overline{\text { Received date: July 14, } 2015}$

Foundation item: Natural Science Foundation of Jiangsu Province (BK20130192); Fundamental Research Funds for the Central Universities (2012QNA11, 2013RC13, 2014YC08)

Corresponding author: Li Yanfeng, Ph. D., Professor, School of Chemical Engineering and Technology, China University of Mining and Technology, Xuzhou 221116, P. R. China, Tel: 0086-516-83884442, E-mail: 1yf3344@cumt.edu.cn

Copyright $($ C 2016, Northwest Institute for Nonferrous Metal Research. Published by Elsevier BV. All rights reserved. 


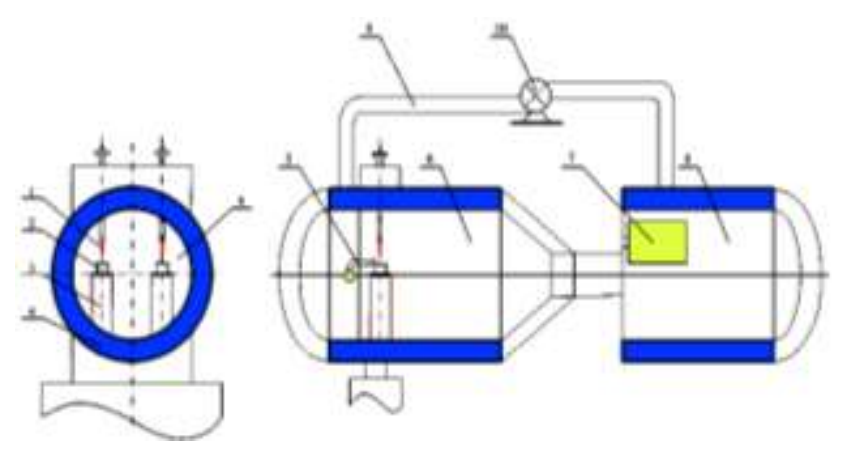

1 tungsten electrode; 2 crucible; 3 water-cooled copper mould;

4 water-cooled chamber; 5 pressure gage; 6 work chamber;

7 filtration fabric; 8 collected chamber; 9 circulating gas path;

10 circulating fan

Fig.1 Schematic drawing of device of continuous preparing nanometer-scale metallic powders

work chamber and collected chamber. After the work chamber was cleaned and vacuum-pumped substantially, it was filled with $\mathrm{Ar}$ and $\mathrm{H}_{2}$ with a certain volume ratio of 7 to 3 . Then the plasma arc was triggered and the work current was kept as 600 A. Under the action of the plasma arc, raw material (bulk coarse-grained $\mathrm{Ni}$ ) was evaporated rapidly in this experiment.

Simultaneously, the metal steam was forced into a watercooled cylinder that acted as a powder collected chamber by a blower and condensed rapidly into powders with nanometer gain size on filtration fabric or walls of the water-cooled cylinder.

Subsequently, the evaporated powder was pressed in a die under a compaction pressure of $1950 \mathrm{MPa}$ for $5 \mathrm{~min}$ at room temperature, and then the green samples were reloaded and sintered at $725^{\circ} \mathrm{C}(0.58 \mathrm{Tm})$ under the pressure of $35 \mathrm{MPa}$ for $1 \mathrm{~h}$. Another sintering at no pressure for $1 \mathrm{~h}$ under the protection of inert gas, was performed at the same temperature. During the sintering process, a constant elevation rate of temperature was $10^{\circ} \mathrm{C} / \mathrm{min}$. The resultant cylindrical samples were $8 \mathrm{~mm}$ in diameter and $4 \mathrm{~mm}$ in thickness. The microstructures of the powder and the sintered samples were investigated by X-ray diffraction (XRD) and transmission electron microscope (TEM). The density of the sample was measured according to the Archimedes method.

Finally, the quasi-static tests were preformed on a MST 880 Material Test System under unaxial compressive loading at strain rate of $10^{-4}, 10^{-3}$ and $10^{-2} \mathrm{~s}^{-1}$. The sample compressed at $10^{-3} \mathrm{~s}^{-1}$ was examined by XRD and TEM for observing the evolution of microstructure after compression.

\section{Results and Discussion}

\subsection{Microstructure of powder and bulk NC Ni}

Fig. 2 shows the TEM image of the NC Ni powder prepared by the plasma evaporation method. It reveals that spherical and regular crystalline is formed during the evaporation process and the particles of NC Ni crystalline have a narrow

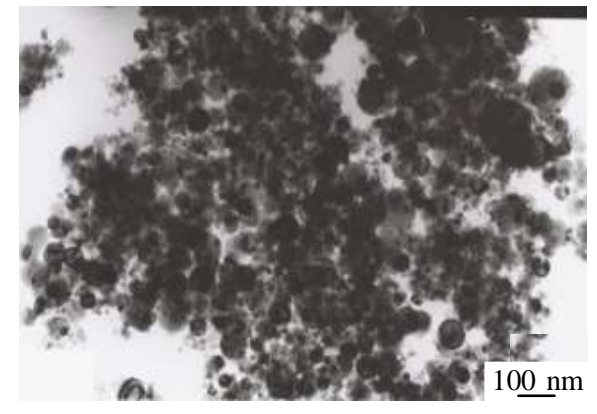

Fig.2 TEM image of $\mathrm{NC} \mathrm{Ni}$ powder prepared by the plasma evaporation method

grain size distribution. This is beneficial for generating a homogenous nano-structure of $\mathrm{Ni}$ bulk during subsequent compaction and sintering. According to the TEM image, the average particle size of the powders is about $45 \mathrm{~nm}$. So the plasma evaporation method can produce well-distributed NC particles. Fig. 3 gives the representative TEM bright field image together with the corresponding selected area diffraction (SAD) pattern of the grain morphology of the bulk NC Ni sample after compaction and sintering. The shapes of the grains are mainly equiaxed and the average grain size of the bulk sample is about $75 \mathrm{~nm}$ after compaction and sintering, which increases by 2 times from the initial powder stage approximately. This can be attributed to the growth of crystal at high temperature during sintering. However, the grain size of the Ni bulk is still in the nano-scale. The closest first and second rings of the SAD pattern in the inset of Fig.3, correspond to the $\{111\}$ peak and $\{200\}$ peak of the Ni fcc structure, respectively. Interplanar distances measured from the corresponding diffraction rings have a good agreement with standard ones of pure fcc $\mathrm{Ni}$, suggesting no second phase is present in NC Ni bulk sample. Moreover, the observation of the microstructure reveals no clear evidence for the present of dislocations in NC Ni bulk.

\subsection{Mechanical behaviors of the bulk NC Ni}

Fig.4 reveals true stress-strain curves of bulk $\mathrm{NC} \mathrm{Ni}$ samples after compaction and sintering at different quasi-static strain rates. The bulk samples have a good density, and the relative density of the bulk obtained by Archimedes method reaches $99.6 \%$. It is obvious from Fig. 4 that the bulk samples exhibit a good combination of strength and ductility. The yield strength of the sample is 6 7 times higher than that of coarse-grained polycrystalline counterpart. At the same time, the compression flow strength increases and the ductility decreases with increasing of strain rate, which suggests that the compression stress-strain curves of the bulk NC Ni exhibit rate-dependence. However, the strain hardening behavior of the samples is not obvious and the bulk NC Ni presents light strain hardening, which is not identical with coarse grained $\mathrm{Ni}$. These mechanical behaviors may be caused by a special deformation mechanism in NC bulk. In the following section, 


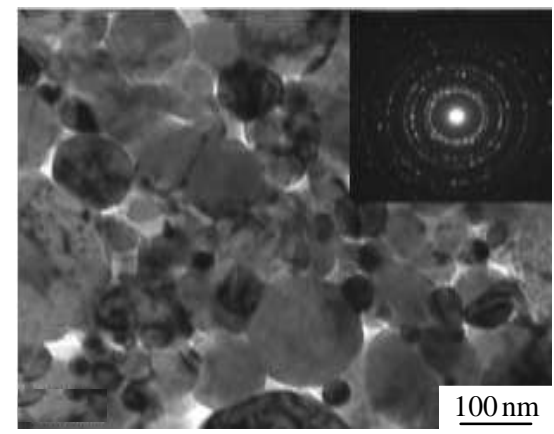

Fig.3 TEM image together with the corresponding selected area diffraction pattern of the grain morphology of the bulk NC Ni sample after compaction and sintering

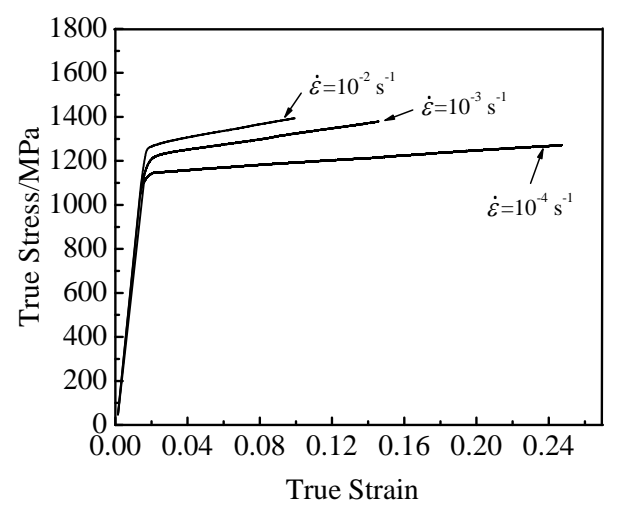

Fig.4 True stress-strain curves of bulk NC Ni samples at quasi-static strain rate

we will discuss the underlying plastic deformation mechanism of the bulk NC Ni in details.

\subsection{Underlying plastic deformation mechanism of the bulk NC Ni}

To understand the plastic deformation mechanism of the bulk $\mathrm{NC} \mathrm{Ni}$, the strain rate sensitivity $(m)$ of the sample was investigated in the present paper. The strain rate sensitivity of strength is a key parameter in evaluating the deformation of $\mathrm{NC}$ metals ${ }^{[17]}$, and the value of the strain rate sensitivity can be determined from the slope to a linear fit for log-log scale plot of flow strength $(\sigma)$ versus strain rate $(\dot{\varepsilon})$, as follows:

$m=\partial(\ln \sigma) / \partial(\ln \dot{\varepsilon})$

Fig.5 shows the flow stress at strain of $3 \%$ and $5 \%$ as a function of strain rate in a logarithm format. From this figure, the mean value of $m$ is about 0.0255 for the bulk NC Ni. It is well known that for coarse-grained fcc metals the dislocation-mediated deformation mechanism should be responsible for the plastic flow and this mechanism is not sensitive to strain rate. On the contrary, the plastic deformation of $\mathrm{NC}$ metals, especially for the metals with tiny grain size $(d<20 \mathrm{~nm})$, is mainly controlled by grain boundary mediated mechanism ${ }^{[18,19]}$. This grain boundary mediated mechanism usually requires the relatively higher value of $m$

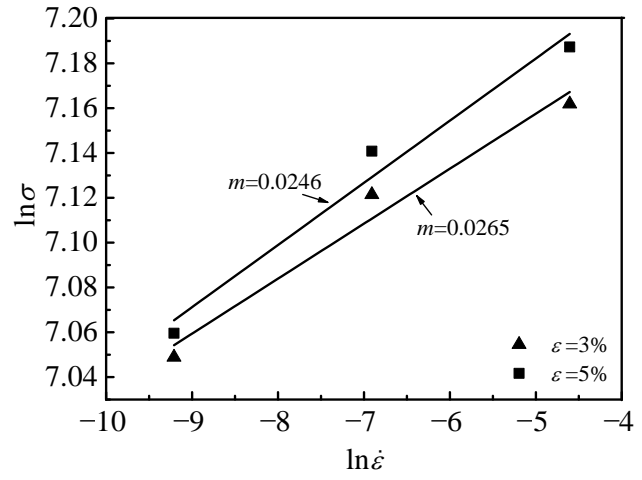

Fig.5 Flow stress at strain of 3\% and 5\% as a function of strain rate in a logarithm forma (the value of the strain rate sensitivity can be obtained from the slope of the plot of $\ln \sigma$ vs $\ln \dot{\varepsilon}$ )

that may be of the order of $0.5 \sim 1$. Whereas, it is clear that the strain rate sensitivity of the bulk NC Ni sample is smaller than that of NC metals with tiny grain size. So the grain boundary mediated mechanism can carry the plastic flow of the bulk NC $\mathrm{Ni}$ sample. It is reasonable that the plastic deformation of these samples in the present paper may be contributed from the combination of the dislocation and grain boundary mediated process. This combined mechanism can be supported by the evolution of the microstructure of the bulk NC Ni sample.

Fig. 6 gives the diffraction line positions $(2 \theta)$ of powder and bulk sample before and after compression on the $\{111\} /\{200\}$ family planes. It can be seen from Fig.6 that XRD patterns of bulk sample after compression show relatively broad peaks compared with that before compression, and this should be attributed to the refinement of crystals, the introduction of internal strains and the instrumental effects. The average grain size and the internal strain of the sample before and after compression can be calculated by Hall-Williamson method:

$$
B_{\mathrm{S}} \cos \theta=K \lambda / d+2 \sin \theta
$$

where $\lambda$ is the wavelength of the $\mathrm{Cu} \mathrm{K} \alpha, B_{\mathrm{S}}$ is the full width at half maximum (FWHM) of the diffraction peak, $K$ is the Scherrer constant $(K=0.9), d$ is grain size, $\varepsilon$ is the internal strain introduced during deformation and $\theta$ is Bragg angle. $B_{\mathrm{S}}$ is given as follows:

$$
B_{\mathrm{S}}^{2}=B_{\text {exp }}^{2}+B_{\text {inst }}^{2}
$$

where $B_{\text {inst }}$ is the FWHM of the standard reference materials used for calibration and $B_{\text {exp }}$ is the FWHM evaluated during the experiment. Fig.7 shows the Hall-Williamson plots. From these curves, the grain sizes of the bulk NC Ni samples can be determined from the intercepts, and the microstrains can be obtained through slops of the plotted straight lines, whose results are listed in Table 1. It is obvious that the grain size of the compressed sample decreases compared with that of the sintered sample, while the microstrain of the grain increases after compression. This indicates that the grain structure is 

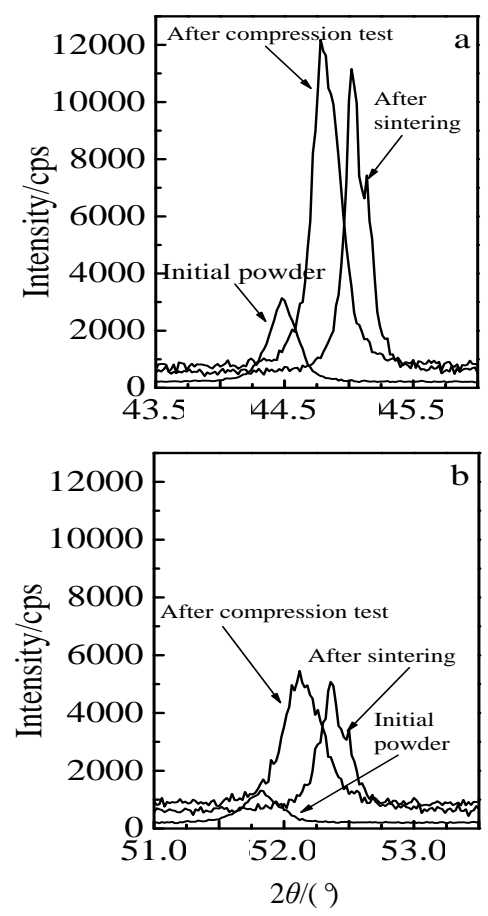

Fig.6 Diffraction line positions (2 $\theta)$ for powders, sample sintered at $725{ }^{\circ} \mathrm{C}$ and compressed at strain rate of $3 \sim 10 \mathrm{~s}^{-1}$ on the $\{111\}$ (a) and $\{200\}$ (b) family planes

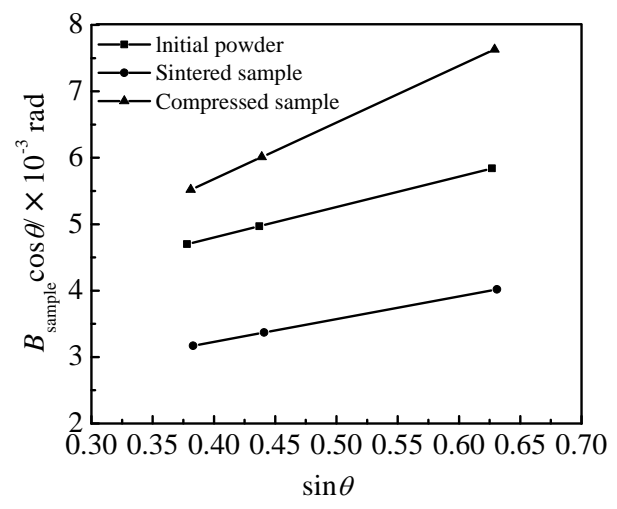

Fig.7 Hall-Williamson plots plotted using (111), (200) and (220) reflection for the initial powder, sintered and compressed sample

unstable during compressive test. For the bulk NC Ni sample prepared by plasma evaporation combined with hot pressure sintering, the decreasing of grain size after compression is controlled by grain boundary mediated mechanism; meanwhile the increasing of microstrain has a relation with dislocation mechanism.

To understand the phenomenon, the concept of statistically stored dislocation (SSD) and geometrically necessary dislocation (GND) ${ }^{[20]}$ is introduced. At small plastic deformation, the SSDs appear firstly in larger grains and are accumulated by random mutual trapping. Nevertheless, when the sample sustains severe plastic deformation, the GNDs will be generated
Table 1 Grain size and microstrain obtained from HallWilliamson method for the initial powder, sintered and compressed sample

\begin{tabular}{cccc}
\hline Sample & Intercept $/ \times 10^{-3}$ & Grain size $/ \mathrm{nm}$ & Microstrain $/ \times 10^{-3}$ \\
\hline Initial powder & 2.97 & 47 & 2.29 \\
Sinter-sample & 1.85 & 75 & 1.72 \\
Compress-sample & 2.31 & 60 & 4.23 \\
\hline
\end{tabular}

to ensure the compatibility of the deformation between grain interior and grain boundary. In this case, the dislocation energy will transfer into grain boundary energy that may be the driving force of grain changing during the deformation of the bulk NC Ni sample. The grain boundary energy per unit volume of grains ${ }^{[21]}$ can be written as follows:

$$
E_{\mathrm{gb}}=4 e / \pi^{1 / 2} d
$$

where $e$ is the grain boundary energy per unit area and $d$ is the grain size. From this equation, the grain size has to decrease with increasing of plastic deformation to provide large enough grain boundary energy, and thus the grain boundary mediated mechanism will be enhanced and dominate it during larger plastic deformation. At the same time, the grain boundary mediated deformation will release the local large stress concentration induced by the accumulation of glide dislocations and delay the onset of the premature damage. So the dislocation glide controlled mechanism accompanied by grain boundary sliding can be used to explain the fact that the bulk NC Ni possesses good ductility without loss of high strength.

To further verify the combined mechanism and confirm the details of grain boundary mediated mechanism, the morphology of the bulk NC Ni after compression was investigated by TEM too, as shown in Fig. 8. It is obvious that the grains of the bulk NC Ni are elongated after compression. This phenomenon suggests that grain boundary sliding which causes the elongation of the grains is main carrier of the plastic deformation of the bulk sample. So grain boundary sliding is the main mode of grain boundary mediated mechanism for the bulk NC Ni sample in the present experiment. However, the grain boundary sliding mechanism can not undertake the plastic deformation only. From Fig.8, there are a few pile-up of dislocation in grain boundary.

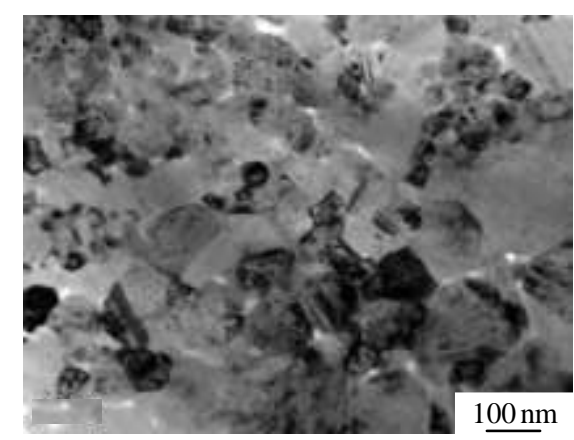

Fig.8 TEM image of the bulk NC Ni after compression at strain rate of $10^{-3} \mathrm{~s}^{-1}$ 
Therefore, a mechanism of dislocation gliding in combination of grain boundary sliding as a carrier of plastic deformation for bulk NC Ni is supposed in the present paper.

\section{Conclusions}

1) The bulk NC Ni samples can be synthesized by a plasma evaporation method combined with compaction and hot sintering, and the consolidated samples exhibit both high yield strength and enhanced ductility.

2) The grain refinement and increasing of microstrain for the bulk NC Ni sample have been observed after compression, because of the combination of dislocation and grain boundary mediated process.

3) Both dislocation and grain boundary mediated deformation mechanisms are predicted for the bulk NC Ni prepared by the plasma evaporation method combined with hot pressure sintering according to the experimental results.

\section{References}

1 Schwaiger R, Moser B, Dao M et al. Acta Materialia[J], 2003, 51: 5159

2 Cheng S, Ma E, Wang Y M et al. Acta Materialia[J], 2005, 53 : 1521

3 Jia D, Ramesh K T, Ma E. Acta Materialia[J], 2003, 51: 3495

4 Kim H S, Estrin Y. Acta Materialia[J], 2005, 53: 765

5 Fu H H, Benson D J, Meyers M A. Acta Materialia[J], 2001, 49: 2567

6 Yang W, Wang H T. Journal of the Mechanics and Physics of
Solids[J], 2004, 52: 875

7 Wei Q, Kecskes L, Jiao T et al. Acta Materialia[J], 2004, 52: 1859

8 Zhu R, Zhang X, Li Y et al. Materials and Design[J], 2013, 49: 426

9 Zhou J Q, Zhu R T, Zhang Z Z. Materials Science and Engineering $A[\mathrm{~J}], 2008,480: 419$

10 Gianola D S, Warner D H, Molinari J F et al. Scripta Materialia [J], 2006, 55: 649

11 Gai P L, Zhang K, Weertman J R. Scripta Materialia[J], 2007, 56: 25

12 Fan G, Fu L, Qiao D et al. Scripta Materialia[J], 2006, 54: 2137

13 Zhu R T, Zhou J Q, Jiang H et al. Mechanics of Materils[J], 2012, 51: 29

14 Fan G J, Fu L F, Choo H et al. Acta Materialia[J], 2006, 54 4781

15 Schiotz J. Materials Science and Engineering A[J], 2004, 375377: 975

16 Gu C D, Lian J, Jiang Z et al. Scripta Materialia[J], 2006, 54 579

17 Nyakiti L O, Jankowski A F. Metallugical and Materials Transaction A[J], 2010, 41: 838

18 Conrad H. Materials Science and Engineering A[J], 2003, 341: 216

19 Asaro R J, Suresh S. Acta Materialia[J], 2005, 53: 3369

20 Ashby M F. Philosophical Magazine[J], 1970, 21: 399

21 Li J G, Umemoto M, Todaka Y et al. Journal Alloys and Compounds[J], 2007, 434-435: 290

\title{
等离子蒸发制备的纳晶镍的压缩变形机理
}

\author{
朱荣涛, 李延锋 \\ (中国矿业大学, 江苏 徐州 221116)
}

\begin{abstract}
摘 要: 与传统粗晶金属材料相比, 纳晶金属具有特殊的变形机理。为了探索纳晶金属的变形机理, 以等离子蒸发结合热压烧结制备的 块体纳晶镍为研究对象, 进行了准静态压缩力学性能测试, 并且利用 XRD 和 TEM 技术对试样压缩前和压缩后的微结构演化进行了研 究。结果表明: 块体纳晶镍表现出较高的压缩强度和较好的韧性, 且强度和韧性均具有率相关性。同时, 纳晶镍压缩变形后晶粒尺寸较 压缩前减小, 但其微应变增加。结合纳晶镍的力学行为和压缩过程中微结构的演化, 预测晶界位错运动和晶界滑移的联合机制是块体纳 晶镍压缩过程中塑性变形的主要机理。
\end{abstract}

关键词: 块体纳晶镍; 力学行为; 变形机理; 微结构

作者简介: 朱荣涛, 男, 1983 年生, 博士, 副教授, 中国矿业大学化工学院, 江苏徐州 221116, 电话: 0516-83884442, E-mail: rtzhu05@126.com 